\title{
"MIND THE GAP": THE TRANSFORMATIVE LEARNING PROCESS OF SECOND LANGUAGE PRACTITIONERS WHEN BECOMING SCHOLARS
}

\author{
Dana Kaplan ${ }^{1}, \&$ Maya Wizel ${ }^{2}$ \\ ${ }^{1}$ Department of Sociology, Political Science and Communication, The Open University (Israel) \\ ${ }^{2}$ Middlebury Language Schools, Middlebury College (VT, USA)
}

\begin{abstract}
This paper is about transformations from knowing to not-knowing and from doing to becoming. The paper's focus is an ongoing research project on a new Doctorate program in Modern Languages studies (DML) and the process that the students in this program undergo when transitioning from being practitioners to becoming novice scholars. This program is part of a conscious effort to create an academic field whereby scholarly and professional types of knowledge are organically co-produced and this interlaced knowledge is expected to fertilize practitioners' professional practices. The program's graduate students are mostly in their mid-career and are motivated to pursue their DML studies for multiple reasons. The necessity of developing a study plan that can foster their transition from practitioners to scholars and help them develop a researcher identity became evident early on. Students were expected to quickly re-adjust their self-image as future theorizers who could carry out independent research and produce original scholarship. While the challenges mentioned above are not unique to this specific doctorate program and are well documented in the extensive scholarship on doctorate students' education, fewer studies have addressed the particular challenges faculty and students face as part of the latter's transition from practitioners to graduate students and novice researchers. Therefore, we ask, what accounts for a successful process of supporting language teachers in becoming novice researchers? Our aim is twofold: first, to detail our pedagogical rationale, dilemmas we faced, and the solutions we carved out; and secondly, to contribute to a nascent discussion on doctorate students' training and academic socialization in applied disciplines. Using Mezirow's adult learning theory of Transformative Learning, we describe the challenge of designing a process of academic socialization that can support adult learners' development and shift in perceptions, skills, and actions. During the first four cohorts of the program, in an introductory course, "Research Foundations," we faced dilemmas regarding reading materials and teaching activities, and collected students' reflections and communications with us, the course professors. Accordingly, the paper explicitly emphasizes our efforts to actively foster a culture of independent learning and a productive learning community by introducing new knowledge and skills. The paper can benefit instructors who design and lead graduate programs for practitioners in any field of practice.
\end{abstract}

Keywords: Higher education, transformative learning, teaching, doctorate supervision, academic socialization.

\section{Introduction}

This paper addresses some of the complex dilemmas and ad-hoc solutions the two authors devised when instructing the first four cohorts of a new doctorate (Doctor of Modern Languages - DML) program specializing in second language teaching and learning. These doctoral students who also work as second language teachers state - in many versions, "This is not in the slightest my everyday experience when teaching! What is written in this article is not true at all!" They are quick to address personal experiences as well-established truths. This anecdote reflects the wide gap in perceptions and academic identity of graduate students who are also practitioners. Boud and Lee (2009) suggest that, recently, a "new interest in the educative work of doctoral programs has surfaced at a time of major social and policy-led change in the field of doctoral research and practice" (p.1). In light of the expansion of graduate education (Altbach, 2015 ) in many national higher education contexts, Boud and Lee further recommend that scholars pay more attention to the "whys" and "hows" of doctoral studies. They argue that the task ahead is to recalibrate both the rationale and actual practices of the Ph.D. training process. Doctoral training is already a transformative process that involves learning new skills, modes of thinking, and ways of being in the world. Yet, it is less clear what might be the best practices to help students socialize into the new "researcher" habitus. The gap 
between the entry and exit points in the doctoral training process has been described as a journey and has been extensively studied (Hughes \& Tight, 2013). However, less attention has been paid to this academic development journey in disciplines that are markedly practice-based (such as, education of applied linguistics). Equally understudied is the training process of students who are already established professionals in their respective fields of practice and who, furthermore, do not conceive of their doctoral studies solely as a segue for an academic career.

Our aim in this paper is twofold. First, we shall survey the specific training challenges in the context of a practitioner doctorate. Secondly, based on our experience as co-instructors of the Research Foundations course of an emerging DML program, we shall provide insights and solutions we devised to help students acquire a researcher's habitus even if they do not plan on becoming full-blown researchers themselves.

\section{Opening the "black box" of the practitioner doctoral training process}

In recent decades, the academic employment market has been extensively restructured, with the rise of the worldwide casualization of academic labor (Whitchurch, 2019). These developments have led to the expansion of applied and practitioner doctorate programs, such as EdD in the field of Education (Wildy, Peden \& Chan, 2015; Hawkes \& Yerrabati, 2018). According to Boud and Lee (2009), a new ideal type of doctoral student is on the rise, as part of a transformation in the way universities "think" and is in tandem with broader societal changes that reshape the role of knowledge and knowledge production in the new global economy (Shin, Kehm \& Jones, 2018). These top-down macro forces have also affected the doctoral training process and led to the diversification of doctoral degrees (Burrington \& Throne, 2021, Shin et al., 2018). Thus, while universities and faculty are still highly committed to the classic "pure" academic research orientation (Teichler, Arimoto \& Cummings, 2013), current higher education trends increasingly approach graduate studies through the prism of non-academic human capital and emphasize the practical applicability of research outcomes (Altbach, 2015; Shin et al., 2018; Wildy et al., 2014). Evidently, the traditional desired end result of the doctoral training process - the academic job - is conceived as neither sustainable nor desirable by many doctoral students themselves. These students may enroll in doctoral programs in order to enhance their employability outside of the traditional academic market by deepening their professional knowledge or for the sake of personal development.

These structural changes challenge many hard-wired truths and training practices in the doctoral education process (Shin et al., 2018). Despite the evident rise in practitioner doctoral programs, there still remains a gap between the social imagining of the university as a site for universal knowledge production and the current demand for applied doctoral training programs (Barcan, 2013). This ambivalence in the role of the University directly translates into the training process of some practitioner doctoral programs. As a new kind of graduate scholar emerges who, besides the required traditional field-specific knowledge, needs to also become research-capable, reflexive and flexible (Shin et al. 2018), the question is, how to we train this "multi-talented" practitioner doctoral scholar?

The tension between practice and scholarship is also experienced by the doctoral students themselves, as the academic environment sends them mixed messages. Practitioner doctoral students are expected to quickly socialize into the new "researcher" role, even if this is not the reason they embarked on this "mountain-climb" in the first place (Burrnigton \& Throne 2021). The first steps of the training process, we contend, are particularly difficult and challenging for both students and instructors and they require a bit of unlearning, too. In the following, we therefore ask, how can practitioner doctoral training simultaneously accommodate the actual needs of students while not betraying the ethos of scholarly habitus?

We are specifically interested in the ways both students and instructors "mind" two kinds of gaps while taking and teaching the course: the gap between research and practice; and the gap between novice and accomplished researchers. Burrington and Throne (2021) suggest that practitioner doctorate leadership should be more reflexive "in the pedagogical redesign of the practitioner doctorate to strengthen the development and preparation of these scholar-practitioners" )p. 64). Following this advice, we ask, how does a "profession-based doctorate" work? What are the challenges both DML candidates and their instructions face in that first, crucial stage of initiation into the researcher's role in the context of a practice-based training program? How are the demands for a doctoral-level education being met for those who do not necessarily wish to proceed to an academic career? What are the affective investments and knowledge bases required in the transition from being a stakeholder in a purely professional field to becoming a novice scholar in the academic world? This paper dissects the "whys" and "hows" of that introductory course, focusing on the experience we, the course instructors, have accumulated over four years of experience in teaching it in the emerging doctorate program for second language teaching at an American university during the years 2016-2021. 


\section{The transformational process}

The challenges mentioned above can be described as a need for a transformational process:

There are [...] fundamental transformational processes comprising threshold concepts and troublesome knowledge that higher degree students have to work through before they are enabled to progress with their studies. Unless these thresholds of learning are crossed and the troublesome knowledge 'managed', students are not transformed nor empowered to move from a space of 'becoming' magisterial students to actually undergoing a shift in identity that moves them into a space of 'being' postgraduate students (Vahed et al., 2018: 317).

One of the best illustrations of the difficulty to cross these troubled waters can be found in our students' tendency to stay in the comfort zone of thinking like a practitioner. This has often served as a hindrance for the required change of values, assumptions, and skills. We wish to describe our pedagogical choices and solutions in light of Mezirow's (1994) adult learning Theory of Transformational Learning. According to Mezirow, learning is "the social process of constructing and appropriating a new or revised interpretation" (p. 222) or meaning-making. Based on their background and previous experiences, individuals have frames of reference, divided into sociolinguistics frames, psychological frames, and epistemological frames. According to Mezirow, adults tend to resist learning, especially parts that are irreconcilable with existing frames. The idea of transformation is dominant in other adult learning theories and we find the definition offered by Stevens-Long et al. (2012) as descriptive and relevant to our case study. They claim that "transformation as an outcome refers to a deep and lasting change, equivalent to what some people term a developmental shift or a change in worldview" (p. 184). Distinguishing between informative learning that creates changes in what we know and transformative learning that promotes changes in how we know, Kegan's (2010) formulation summarizes well the transformative nature of doctoral studies. Based on the above compatible conceptualization, our goal was to instill habits that would enable a shift in existing frames and foster learning and development.

Over the last four years, we have constantly revised the course, tailoring it to address the gap between the students' practitioner frames and the scholarly frames we wanted them to develop. Changes over the years have included formal course goals, reading materials, class design, assignments, types of feedback, and our role as instructors. Together, all these practices were meant to improve the transformational learning process and help students start narrowing the gap. Using some of Mezirow's (1994) recommendations regarding reflection, discourse, and communication, we will now exemplify our teaching practices.

In the first two years of teaching the course, the goals detailed in the syllabus focused on expanding students' knowledge of social sciences epistemology. To this focus on "how scholars know," we later added another transformative layer, indicating that becoming a scholar is a clearly defined goal. This change was not merely semantic. Rather, we devoted much time to explaining the nature of this change and made sure to acknowledge the uncertainty and confusion students felt once they realized that even though they have substantial prior knowledge in being practitioners, they nevertheless still have a lot to learn in the new academic setting. By way of doing what we preach, we anchored their transformative experience in serious scholarship, assigning readings that resonated with their own transformative process (for example: Kiley, 2017).

Mezirow stressed the importance of employing a discourse that advances learners' critical thinking. Following this lead, we gradually adopted a discussion-based, active learning mode. This meant devoting most of the class time to discussions led by the students themselves. Students' active roles as discussion moderators helped them develop scholarly critical skills since they needed to locate gaps in the literature, take a critical approach with the readings, and lead thoughtful, full class discussions. In addition, we utilized our roles as co-instructors and openly debated various epistemological issues, also stressing (rather than down-playing) our disciplinary differences (sociology and education). This demonstrated that polemic is invaluable for the production of academic knowledge. These various communicative practices were geared to "cultivating the learners' ability to negotiate meanings and purposes instead of passively accepting the social realities presented by others" (Mezirow, 1994: 226).

One of our main goals was to foster students to become self-learners. One activity that helped students understand that each student has her own path took place at the beginning of the course. In the second meeting, we asked each participant to create a concept map of topics and questions they find interesting to potentially further inquire. The impact was huge and long-lasting; it showed that each student had her own experiences, passions, and intellectual interests. This activity also helped students realize that much independent work is required and that our role as instructors is to facilitate and support that individual process. The effort to help students develop a self-learners' state of mind led to some frustrating moments. We often resisted giving concrete answers to questions by raising more questions, a process that some 
students appreciated while others felt that they were neglected or abandoned. This was another gap of perceptions and actions that, over time, narrowed.

Research can be a very lonely process; this loneliness can carry with it confusion, frustration, and the risk of losing one's voice (Hughes \& Tight, 2013). In order to tackle these anticipated difficulties, we have dedicated a great deal of effort to building a supportive cohort through much group work, with the reasoning that this could either facilitate or impede students' development during the whole doctorate process (Cusick, 2015). For some participants, this expectation was perceived with reservations. The students were not accustomed to focusing on someone else's ideas, lacked the habits of giving meaningful and productive feedback, and felt that this requirement shifted them from concentrating on their own work. For example, there was a lack of cooperation with tasks that included peer review. It seems that the traditional structure of the professors as the source of knowledge dominated. In the few cases that peer review took place, the students tended to ask for additional feedback from us while expressing the need for more "reliable" feedback. We insisted on the importance of peer feedback and supported creating non-formal communication of the cohort members outside of class time and without our presence.

We shared a number of our teaching decisions and activities for planning and teaching graduate students and helping them close the gap successfully to become scholars. Stevens-Long, Schapiro and McClintock (2012) found multiple key factors for a successful transformative learning process, such as self-reflection, self-direction, and various kinds of interpersonal and community support. We recommend naming this transformation challenge, talking about it, and assigning reading materials that discuss transforming from being a practitioner to being a scholar in an explicit way. Another consideration is to create opportunities for students' reflection. Some students are able to reflect spontaneously but this needs to be encouraged in assignments and during class time to support individuals in this process. One tension that needs addressing while designing such a course is the balance between encouraging self-directed learners while, at the same time, being part of a cohort of learners. It is like having it both ways: encouraging learners to work independently, inquire and become accustomed to the individual aspects of researching while, at the same time, understanding the benefits and the habits that an effective cohort can contribute at any step of the way. Lastly, as discussed earlier, instructors' role in doctorate programs' preliminary courses are important precursors (Cusick, 2015). Part of the goal should be to "walk the talk" and share areas of uncertainty, provide guidance and confidence in the process and, at the same time, allow for independent work and decrease the dependency of students.

The course syllabus is flexible enough to adapt from one cohort to another and from one student to another. We nevertheless see it as a continuous effort to create and sustain a learning environment that supports transformation. Our work has proved successful as one student concluded a two-hour class saying happily that "everything I thought before class is now overturned! I leave class today with more question marks than exclamation points."

\section{References}

Altbach, P. G. (2015). Building an academic career. A twenty-first century challenge. In M. Yudkevich, P., G. Altbach, \& L. Rumbley (Eds.), Young Faculty in the Twenty-first Century: International Perspectives (pp. 5-19). Albany: State University of New York Press.

Barcan, R. (2013). Academic Life and Labour in the New University, Hope and Other Choices. England: Ashgate Publishing Limited.

Boud, D. \& Lee, A. (2009). Changing practices of doctoral education. British Journal of Educational Studies, 57(3), 339-341

Burrington, D. D., \& Throne, R. (2021). Navigating the doctoral labyrinth: Reflexivity as transformative catalyst for practitioner doctorate persistence and completion. In Throne, R. (Ed.), Practice-Based and Practice-Led Research for Dissertation Development (pp. 64-86). USA: IGI Global.

Cusick, A. (2015). Research training as occupational socialization: Doing research and becoming researchers. Asian Social Science, 11(2), 252-261.

Hawkes, D. \& Yerrabati, S. (2018). A systematic review of research on professional doctorates. London Review of Education. 16(1), 10-27.

Hughes, C. \& Tight, M. (2013) The metaphors we study by: the doctorate as a journey and/or as work. Higher Education Research \& Development, 3(5), 765-775.

Kegan, R. (2000). What "form" transforms?: A constructive-developmental approach to transformative learning. In J. Mezirow (Ed.) \& Associates, Learning as Transformation (pp. 3-34). San Francisco: Jossey-Bass.

Kiley, M. (2017). Career professionals entering doctoral study: Advantages and challenges. Innovations in Education and Teaching International, 54(6), 550-559. 
Mezirow, J. (1991). Transformative Dimensions of Adult Learning. San Francisco: Jossey-Bass.

Mezirow, J. (1994). Understanding transformation theory. Adult Education Quarterly, 44(4), 222-232.

Patterson, C.A., Chang, C.-N., Lavadia, C.N., Pardo, M.L., Fowler, D.A. and Butler-Purry, K. (2019), Transforming doctoral education: preparing multidimensional and adaptive scholars. Studies in Graduate and Postdoctoral Education, 11(1), 17-34.

Shin, J. C., Kehm, B. M., \& Jones, G. A. (2018). Doctoral Education for the Knowledge Society. Cham: Springer.

Stevens-Long. J, Schapiro, S. A, McClintock, C. (2012). Passionate Scholars: Transformative Learning in Doctoral Education. Adult Education Quarterly: A Journal of Research and Theory, 62(2), 180-198.

Teichler, U., Arimoto, A., \& Cummings, W. K. (2013). The Changing Academic Profession. Dordrecht: Springer.

Vahed, A., Ross, A. Francis, S., Millar, B., Mtapuri, O. \& Searle, R (2018). Research as transformation and transformation as research. In Bitzer, E., Frick, L., Fourie-Malherbe, M. \& Pyhältö, K. (Eds.). Spaces, Journeys and New Horizons for Postgraduate Supervision. (pp.315 - 334). Stellenbosch: Sun Press.

Whitchurch, C. (2019). From a diversifying workforce to the rise of the itinerant academic. Higher Education, 77(4), 679-694.

Wildy, H., Peden, S. \& Chan, K. (2015). The rise of professional doctorates: case studies of the Doctorate in Education in China, Iceland and Australia. Studies in Higher Education, 40(5), 761-774. 